\title{
DESIGN AND FABRICATION OF VARIABLE WHEELBASE PLATFORM FOR PASSENGER AND COMMERCIAL ELECTRIC VEHICLE
}

\author{
Varun V More', Atul A Gurav², Siddhesh K Patade ${ }^{3}$, Manuja Pandey ${ }^{4}$ \\ ${ }^{1}$ Student, Department of Mechanical Engineering \\ ${ }^{2}$ Student, Department of Mechanical Engineering \\ ${ }^{3}$ Student, Department of Mechanical Engineering \\ ${ }^{4}$ Assistant Professor, Department of Mechanical Engineering, MGMCET, Kamothe
}

\begin{abstract}
The variable wheelbase platform aims at reducing the vehicle space usage on the road, which in turn can help with reducing the traffic congestions and also with the parking space crisis faced by many metropolises now. The platform is designed in such a way that the vehicle will have easy, safe and stable maneuverability even at higher speeds. To ensure that the chassis is safe and stable in expanded as well as in contracted wheelbase conditions different mechanisms are used for the expansion of the wheelbase and for its locking. These mechanisms will also be electrically powered to ensure smooth functioning.
\end{abstract}

The concept of the platform which can be used commonly for both, the commercial as well as passenger electric vehicles can be considered as a modern approach when the automobile industry is moving towards reducing the manufacturing cost, scraps and provide more features to the consumers. The platform being designed exclusively for electric power transmission ensures that the project concept is future ready and eco friendly. The concept of the variable wheelbase also helps us to have a modular approach in designing the vehicles ahead.

In this project, the platform has been analysed in its expanded as well as contracted wheelbase condition for different parameters (like Compression Strength Analysis, Torsion Analysis, Factor of Safety). The Expansion and the locking mechanisms too have been analysed for their strength and load bearing capacity. The Power Screw and the linear bearings which are used to power the expansion are also analysed to test and certify their endurance limit. All the Computer Aided Designing and the analysis is been done on the SOLIDWORKS 2016 software.

Keywords: variable wheelbase, traffic congestion, future concept, eco friendly and modular approach, etc. $* * *$

\section{INTRODUCTION}

In this project we have aimed to design a platform which can be easily used to design and manufacture passenger as well as commercial segment vehicles. Keeping in mind the future trend of electric vehicles, the platform designed is such that it can be exclusively used in electric vehicles having the rear end electrically power drive train system. The use of separate expansion and locking mechanisms ensures the safety and the reliability of the structure as per the considered international automobile safety standards. Thorough analysis is done considering various parameters to validate the design considerations. The parameters considered consist of suspension system mounting provision, steering and brake assembly mounting provision. The vehicles then designed on this concept can effectively increase or reduce their wheelbase as per the consumer needs. The finite element analysis has been shown to be a valuable tool in performing the stress analysis and evaluation of other quantities. Mechanism which will also guarantee the structural safety the expansion mechanism resides in the rear part of the platform. The frontal portion is designed keeping in mind the conventional design parameters, the rear portion housing the expansion mechanism is modeled for having the perfect meshing of the movable sections of the platform.

\subsection{Literature}

Manpreet Singh Bajwa (2013) [1] present the static load analysis excluding damping and inertia effects of the chassis of TATA super ace using ansys . Chassis is tasked at holding all the essential components of the vehicle like engine, suspension, gearbox, braking system, propeller shaft, differential etc. To sustain various loads under different working conditions.

Chun-Min Lu, Taipei Hsien (2007) [14] A hidden type sliding rail assembly auto locking structure for drawer comprised of a holder base, a slide ,a locking block and actuating block. When the outer sliding rail is moved outwards with the drawer, the actuating block push the steel spring strip to force the hook against the slide and holder base to prevent the disconnection of locking block. 
Mohamad Sazuan Bin Sarifudin (2012) [2] objective of this project to design and analyse of car chassis. To avoid any possibilities of failure of the structure and thus to provide enough supporting member to make the region stronger in term of deformation. Finite element analysis enables to predict the region that tends to fail due to loading. The main objective is to study the effect of load that applied in term of driver weight, the car body and the equipment.

Hossein sheikhha, Frank Seifert (2010) [3] developed a motor vehicle comprises enclosed bodywork, where the vehicle can be lengthened through relocation of rear axle in longitudinal direction. The vehicle can be shortened when rear seat in not utilised.

Sandip Godse , Prof. D.A.Patel (2013) [4] presents the static load analysis of the chassis of TATA ace using Analysis. This work involved static analysis to determine key characteristics of a chassis. The static characteristics include identifying location of high stress area.

Suraj B Patil , Dinesh G Joshi (2015) [5] aims to provide insight into truck chassis analysis and act as a guide for researchers working on Finite Element Analysis (FEA).

Monika S. Agrawal (2015) [6] to produce results to rectify problems associated with structures of a commercial vehicle such as strength, stiffness and fatigue properties along with stress, bending moment and vibrations. This can be achieved by static and dynamic analysis and advanced analytical method.

William Lark, Jr. (2005) [7] Research focused on developing an innovative, yet simple automobile platform that maximizes its efficiency through shared convenience.

Thin-Lin Horng (2013) [7] is to construct the fatigue life model of the linear guideway, with the help of the contact mechanics of rollers. The normal contact pressure of linear guideways was obtained by using the superposition method, and verified by the FEM software (ANSYS workbench).

Roy H. Tull, Long Beach, Calif. (1937) [15] adapted for extending the rear frame section of the vehicle in order to take care of the diversified lengths of the transporting ware such as I-beams, pipes or other merchandise as in practice may be necessary to transport, so that, while driving an empty vehicle it may be contracted to form a short truck or vehicle.

Clarence W. Kronbetter, St. Joseph (1991) [16] developed a latching mechanism for automatically locking, and selectively unlocking, opposed first and second sliding members

Kenneth B. Jacobs (1996) [17] A rail frame assembly for a motor vehicle comprises a rearward frame module having a pair of generally parallel rearward frame rail members interconnected by a rearward cross-member assembly.
William Andrews (2000) [9] present invention relates to motor vehicles and particularly, though not exclusively to vehicles capable of performing heavy duty work functions such as loading and more particularly relates to improvements in the construction, operation and stability of such vehicles. More particularly the invention relates to a variable geometry vehicle wherein at least the wheel base can be extended to provide a counterbalance for loading which would otherwise tend to destabilise the vehicle.

Francois de Gaillard (2003) [11] invention relates to a motor vehicle with a convertible. It discloses a motor vehicle which has a front Window frame can be moved to the rear in the lengthwise direction of the motor vehicle, and which is guided within a side Wall of the lower part of the body. This movable rigid roof part allows open driving in the without the roof part having to be removed from the motor vehicle passenger compartment.

Michael J. Flowers, Edward J. Hanker (2001) [18] had developed a variable wheelbase personal mobility vehicle comprising a front wheel assembly and a rear wheel assembly. A front wheel is pivot ably mounted relative to the front wheel assembly for controlling the direction of movement of the personal mobility vehicle. Plural drive wheels are mounted relative to the rear wheel assembly for driving the personal mobility vehicle. The variable wheelbase mechanism includes a lock for locking the distance between the front wheel and the plural drive wheels with the lock in a closed condition. The lock enables the distance between the front wheel and the plural drive wheels to be varied with the lock in an open condition.

Katsunori Asogawa (2007) [19] had invented A variable wheel positioning vehicle has a wheel position changing mechanism and a wheel position control device to change a wheel position of a wheel with respect to a centre of gravity of a vehicle body

\section{WORKFLOW \& COMPONENTS}

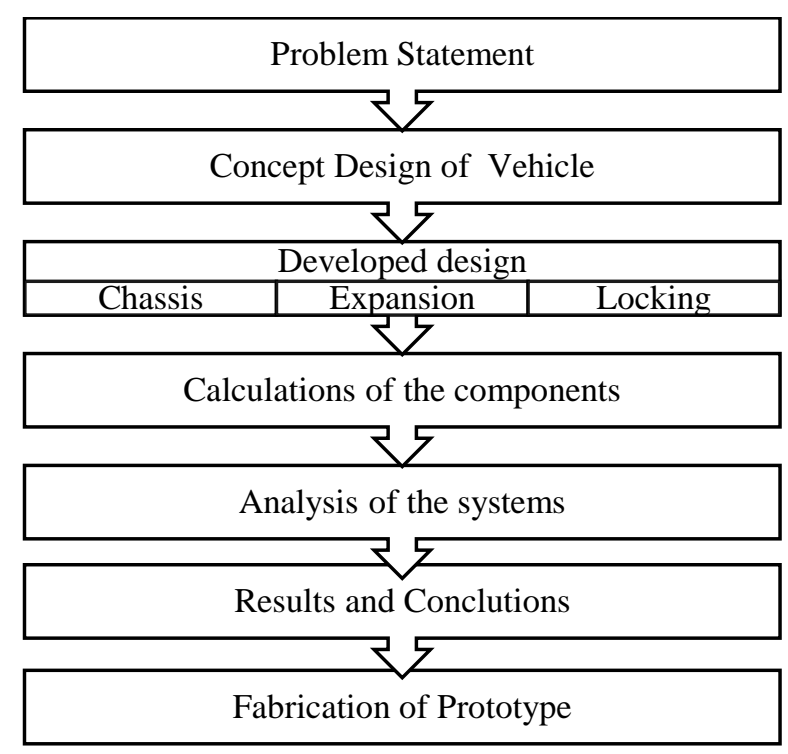

Flowchart 


\subsection{Chassis Design}

As the ladder frame type chassis was selected for designing variable wheelbase vehicle, the conceptual designing was done with same considerations. While designing the chassis the parameters to be considered are ergonomics, suspension mountings, seating capacity.

The first step in designing any vehicle is concept design and sketching, to illustrate how the vehicle will look like, overall dimensions and proportions. Our concept is that of small electric urban vehicle having capability to extend or reduce its wheelbase keeping overall body dimensions in proportion and supporting the counterparts to enhance its telescopic characteristics. Vehicle concept is designed considering to replace the odd looking E-rickshaw and small commercial electric vehicles present in India and other global markets. Our task in this project is design and develop variable wheelbase platform for vehicle which can be used for both style commercial and passenger. Overall wheelbase and dimensions are taken considering the various small vehicles vehicle currently present in the market. The parameters of the vehicle after designing are stated as follows:

Table 4.1 Vehicle Platform Specifications.

\begin{tabular}{|l|l|}
\hline Wheelbase (before expansion) & $1500 \mathrm{~mm}$ \\
\hline Wheelbase (after expansion) & $2000 \mathrm{~mm}$ \\
\hline Track width & $1200 \mathrm{~mm}$ \\
\hline Height of the vehicle & $1200 \mathrm{~mm}$ \\
\hline Gross weight & $450 \mathrm{~kg}$ (approx.) \\
\hline
\end{tabular}

The material to be used is the Plain Carbon Steel AISI 1020 for fabricating the chassis. The ease of availability, high machinability, high strength high ductility, good weldability, lower purchase cost along with adequate force bearing strength proves to be positive aspects in its selection.

Table 4.2: chassis material properties

\begin{tabular}{|l|l|}
\hline Property & Imperial Value \\
\hline Density & $7.87 \mathrm{gm} / \mathrm{cc}$ \\
\hline Brinell Hardness & 111 \\
\hline Ultimate Tensile Strength & $394.72 \mathrm{MPa}$ \\
\hline Yield Tensile Strength & $294.74 \mathrm{MPa}$ \\
\hline Bulk Modulus & $140 \mathrm{GPa}$ \\
\hline Poisson Ratio & 0.290 \\
\hline
\end{tabular}
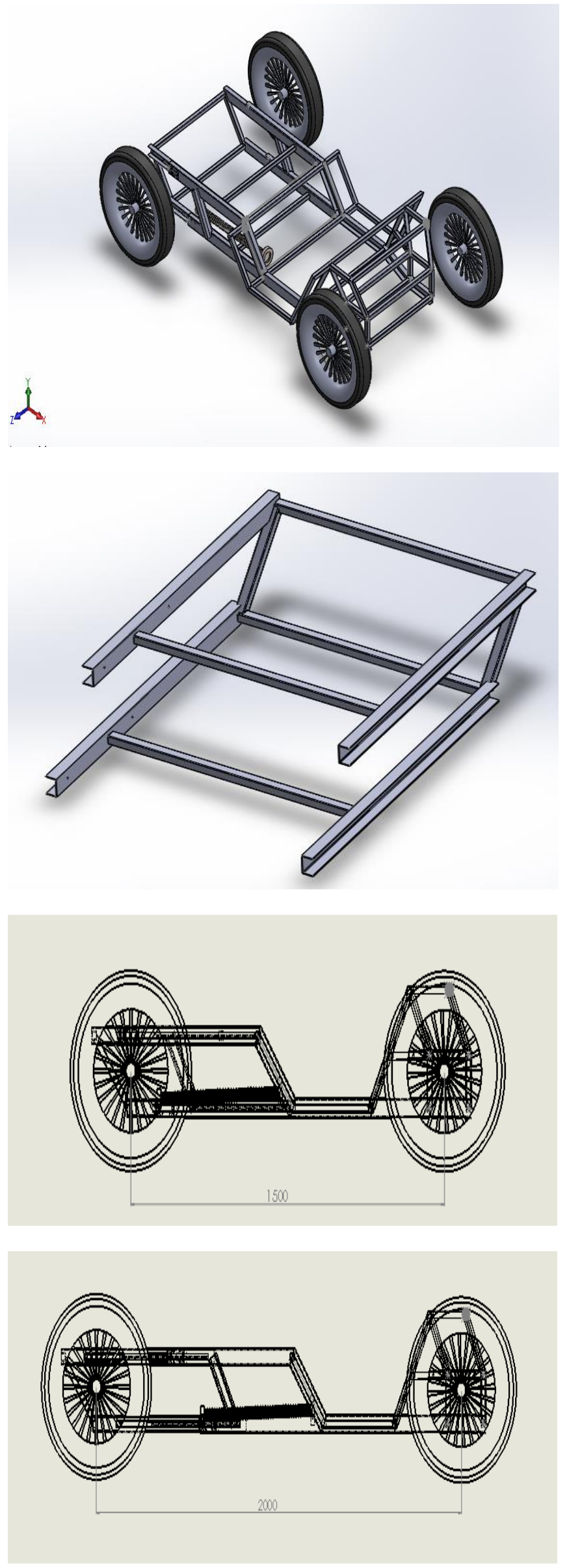


\subsection{Sliding Mechanism}

To maintain smooth and constraint motion while expanding and contracting the counter parts, telescopic arrangement of chassis has been already considered. But to ensure unrestricted meshing of counter parts a strong conjoining element is required in between. To mitigate such requirements out of the all possible entities, it is found that linear bearings are the most suited for the stated operation due to its high strength, efficiency, and high load carrying capacity in three directions. [10]

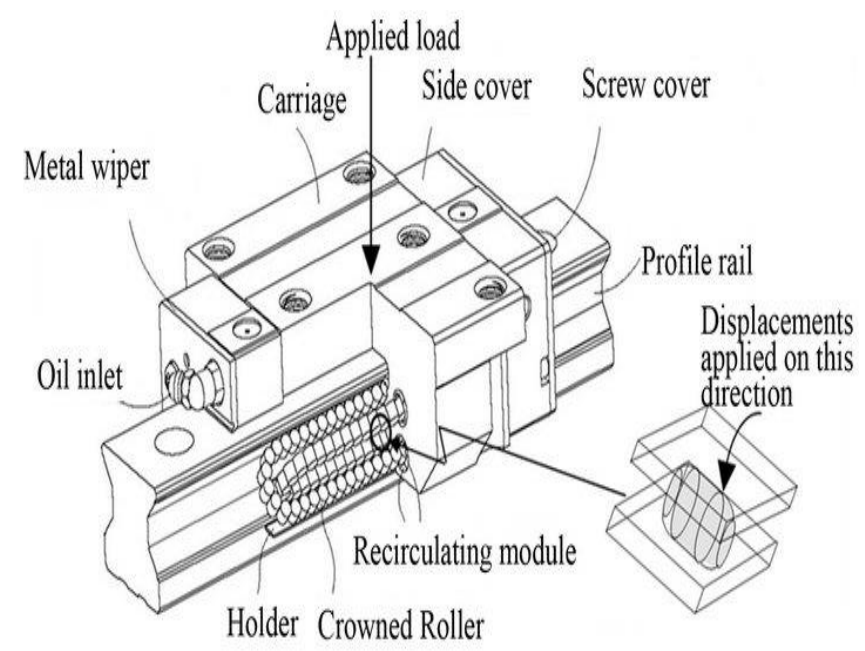

Bearing calculations and selection

The rating life of a bearing for a particular application can be calculated from the following equations

$$
\begin{gathered}
L=\left[\frac{\mathrm{fh}}{f_{w}} \cdot \frac{C}{P}\right]^{3} 2 * 10^{6} \\
L(k m)=\left[\frac{f_{h}}{f w} \cdot \frac{C}{P}\right]^{3} * 50 \\
\mathrm{~L}_{H}=\frac{L}{2 . L_{s} n \cdot 60}
\end{gathered}
$$

Where;

$\mathbf{L}=$ rating life in inches for inch calculations, in Kilometers for metric calculations

$\mathbf{f h}=$ hardness factor (1.0); shafts are 60-65 HRC

$\mathbf{f w}=$ load coefficient (refer to table 1 )

$\mathbf{C}=$ basic design load rating in pounds for inch calculations, in Newtons for metric calculations

$\mathbf{P}=$ force in pounds for inch calculations, force in

Newtons for metric calculations, determined from

load calculation diagrams 1 through 5,

$\mathbf{L h}=$ Life in hrs

Ls = stroke length

$\mathbf{n}=$ rating in cycles per min

Hence, basic dynamic load rating can be given by;

$$
C=\sqrt[3]{\frac{L}{50}} \frac{F W}{F h} * P
$$

\begin{tabular}{|l|l|}
\hline $\mathbf{f}_{\mathbf{w}}$ & Operating condition \\
\hline $1-1.5$ & low speed $15 \mathrm{~m} / \mathrm{min}$ without shock \\
\hline $1.5-2$ & Intermediate speed $60 \mathrm{~m} / \mathrm{min}$ without shock \\
\hline $2-3.5$ & High speed $60 \mathrm{~m} / \mathrm{min}$ with shock \\
\hline
\end{tabular}

load coefficients

Calculations:

no. of linear bearings $=4$

Lh for 10 years

$\mathrm{Lh}=10 * 365 * 24=87600$

weight on carriage $=500 \mathrm{~kg}$

$\mathrm{P}=$ load per bearing $=500 / 4$

$=125 \mathrm{~kg}$

travelling speed $=3 \mathrm{~m} / \mathrm{min}$

$\mathrm{L}=\mathrm{Lh} * 2 * \mathrm{Ls}^{*} \mathrm{n} * 60$

$\mathrm{L}=87600 * 2 * 1000 *(3000 / 2 * 1000) * 60$

$\mathrm{L}=1.57 * 10^{10} \mathrm{~mm} / \mathrm{stroke}$

Hence

$$
\begin{aligned}
& C=\sqrt[3]{\frac{1.57 * 10^{10}}{50 * 10^{6}}} \frac{1.8}{1} * 125 \\
& C=1531 \mathrm{kgf} / \mathrm{mm}^{2}
\end{aligned}
$$

\section{Bearing Selection}

The assumption is that rear part would be carrying half the weight of the total car with passengers ie $500 \mathrm{~kg} \&$ it would be divided qually among bearing as each linear bearing is supposed to carry $1531 \mathrm{kgf}$ i.e $15 \mathrm{kN}$. 


\begin{tabular}{|c|c|c|c|c|c|c|c|c|c|c|c|c|c|c|c|c|c|c|c|c|c|c|c|c|c|c|c|c|}
\hline \multirow{3}{*}{ Model No. } & \multicolumn{3}{|c|}{ Outer dimensions } & \multicolumn{9}{|c|}{ LM block dimensions } & \multicolumn{7}{|c|}{ LM rail dimensions } & \multicolumn{2}{|c|}{\begin{tabular}{|c|}
$\begin{array}{c}\text { Basic load } \\
\text { rating }\end{array}$ \\
\end{tabular}} & \multicolumn{5}{|c|}{ Static permissible moment $\mathrm{kN}-\mathrm{m}^{\circ}$} & \multicolumn{2}{|c|}{ Mass } \\
\hline & Height & Width & Length & & & & & & & & & $\begin{array}{l}\text { Grease } \\
\text { nipple }\end{array}$ & & Width & & Height & Pinch & & Length" & C & $C_{0}$ & 를 & $\begin{array}{l}\mathrm{M} \\
\mathrm{B} \\
\mathrm{B}\end{array}$ & है & $\begin{array}{l}M \\
g \\
\end{array}$ & लि & $\begin{array}{l}\text { LM } \\
\text { block }\end{array}$ & $\begin{array}{l}\mathrm{LM} \\
\text { rail }\end{array}$ \\
\hline & M & W & L & B & C & $s \times l$ & Li & $\mathrm{T}$ & K & $\mathrm{N}$ & $E$ & & $H_{2}$ & $\begin{array}{c}W_{1} \\
\pm 0.05 \\
\end{array}$ & W & M & $F$ & $d_{1} \times d_{2} \times h$ & Max & $\mathrm{kN}$ & $\mathrm{kN}$ & \begin{tabular}{|c|}
1 \\
block \\
\end{tabular} & $\begin{array}{l}\text { Double } \\
\text { blocks }\end{array}$ & $\begin{array}{c}1 \\
\text { block }\end{array}$ & \begin{tabular}{|l|} 
Double \\
Elocks \\
\end{tabular} & \begin{tabular}{|c|c|}
1 \\
\\
block
\end{tabular} & $\mathrm{kg}$ & $\mathrm{kg} / \mathrm{m}$ \\
\hline $\begin{array}{l}\text { HSR 15R } \\
\text { HSR 15RM } \\
\end{array}$ & 28 & 34 & 56.6 & 26 & 26 & $M 4 \times 5$ & 38.8 & 6 & 23.3 & 8.3 & 5.5 & PB10218 & 3.5 & 15 & 9.5 & 15 & 60 & $4.5 \times 7.5 \times 5.3$ & $\begin{array}{c}3000 \\
(1240) \\
\end{array}$ & 8.33 & 13.5 & 0.0805 & 0.457 & 0.0805 & 0.457 & 70.0844 & 0.18 & 1.5 \\
\hline $\begin{array}{l}\text { HSR 20R } \\
\text { HSR 20RM }\end{array}$ & 30 & 44 & 74 & 32 & 36 & $M 5 \times 6$ & 50.8 & 8 & 26 & 5 & 12 & B-M6F & 4 & 20 & 12 & 18 & 60 & $6 \times 9.5 \times 8.5$ & $\begin{array}{r}3000 \\
(1480) \\
\end{array}$ & 13.8 & 23.8 & 0.19 & 1.04 & 0.19 & 1.04 & 0.201 & 0.25 & 2.3 \\
\hline $\begin{array}{l}\text { HSR 20LR } \\
\text { HSR 20LRM }\end{array}$ & 30 & 44 & 90 & 32 & 50 & $M 5 \times 6$ & 66.8 & 8 & 26 & 5 & 12 & B-M6F & 4 & 20 & 12 & 18 & 60 & $6 \times 9.5 \times 8.5$ & $\begin{array}{c}3000 \\
(1480)\end{array}$ & 21.3 & 31.8 & 0.323 & 1.66 & 0.323 & 1.66 & 0.27 & 0.35 & 2.3 \\
\hline $\begin{array}{l}\text { HSR 25R } \\
\text { HSR 25RM } \\
\end{array}$ & 40 & 48 & 83.1 & 35 & 35 & $M 6 \times 8$ & 59.5 & 9 & 34.5 & 10 & 12 & B-M6F & 5.5 & 23 & 12.5 & 22 & 30 & $7 \times 11 \times 9$ & $\begin{array}{l}3000 \\
(2020)\end{array}$ & 19.9 & 34.4 & 0.307 & 1.71 & 0.307 & 1.71 & 0.344 & 0.54 & 3.3 \\
\hline
\end{tabular}

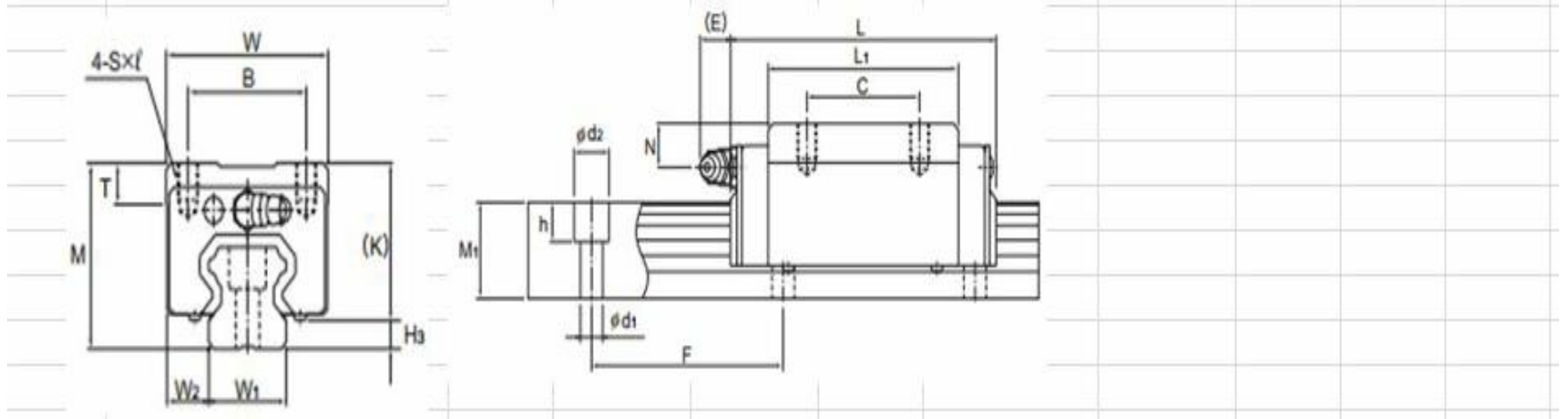

\section{Catalogue Bearing}

Based on the load rating (C) Selecting Linear Bearing From Standard Chart Provided by Hiwin Pvt.Ltd . The mounting of the linear bearing on the side member (made of $\mathrm{C}$ channel) of the chassis is shown as follows:

\section{HSR20LR/ HSR20LRM}

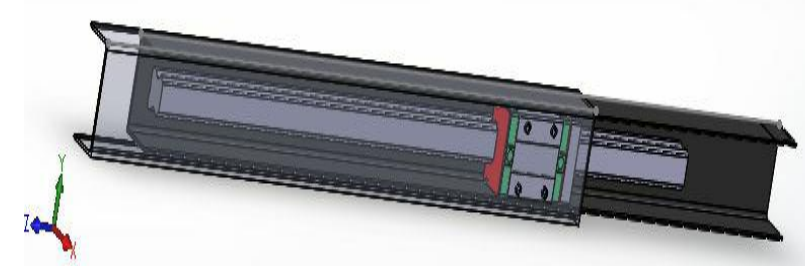

\subsection{Power Screw Mechanism}

The proper mechanism for expansion of the platform (wheelbase) is essential for the stability and maintaining the strength of the chassis, as the requirement here is to have high torque power transmission at lower speed. Also the mechanism used for expansion should be able to bear higher loads. Therefore with considerations of such factors the use of power screw in expansion mechanism was considered.

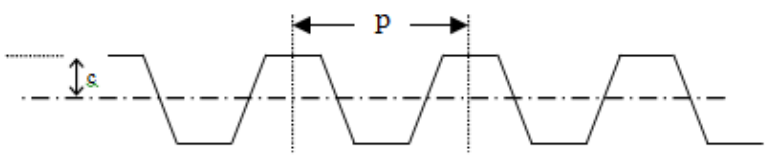

ACME Thread

The dimensions of the designed power screw are:

\begin{tabular}{|l|l|}
\hline$d=36 \mathrm{~mm}$ & $\mathrm{r}=0.25 \mathrm{~mm}$ \\
\hline $\mathrm{p}=6 \mathrm{~mm}$ & $\mathrm{e}=2.06 \mathrm{~mm}$ \\
\hline $\mathrm{t} 1=3.25 \mathrm{~mm}$ & $\mathrm{~d} 1=29.5 \mathrm{~mm}$ \\
\hline $\mathrm{D}=36.5 \mathrm{~mm}$ & $\mathrm{~T} 1=2.75 \mathrm{~mm}$ \\
\hline $\mathrm{D} 1=31 \mathrm{~mm}$ & $\mathrm{a}=0.25 \mathrm{~mm}$ \\
\hline $\mathrm{d} 2=33 \mathrm{~mm}$ & $\mathrm{~b}=0.75 \mathrm{~mm}$ \\
\hline $2 \alpha=29^{\circ}$ & \\
\hline
\end{tabular}

Now, on expansion the vehicle aims at increasing the wheelbase by $500 \mathrm{~mm}$. Therefore considering the length of expansion, clearance the total length of power screw is considered as $(\mathrm{L})=600 \mathrm{~mm}$

Also the numbers of revolutions of the thread are; $=99.5$ revs.

The force acting on the power screw (keeping in mind the weight of the chassis and the passenger) is considered as = $3000 \mathrm{~N}$.

To move the load an axial force is needed. . Here $\mathrm{N}$ is the normal reaction and $\mu \mathrm{N}$ is the frictional force. For equilibrium:

$\mathrm{P}-\mu \mathrm{N} \cos \alpha-\mathrm{N} \sin \alpha=0$

$\mathrm{F}+\mu \mathrm{N} \sin \alpha-\mathrm{N} \cos \alpha=0$

This gives;

$\mathrm{N}=\mathrm{F} /(\cos \alpha-\mu \sin \alpha)$

$\mathrm{P}=\mathrm{F}(\mu \cos \alpha+\sin \alpha) \div(\cos \alpha-\mu \sin \alpha)$ 

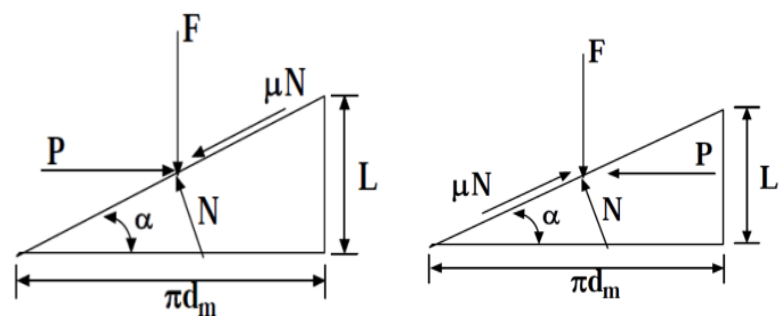

F.B.D. of Screw thread

Torque transmitted during raising the load is then given by;

$$
\begin{gathered}
\mathrm{TR}=\mathrm{P} * \mathrm{dm} / 2=\mathrm{F} * \mathrm{dm} / 2 *(\mu \cos \alpha+\sin \alpha) \div(\cos \alpha-\mu \sin \alpha) \\
\mathrm{TR}=3000 * 7.38 / 2 *(0.5 \text { 2*7.38* } \sec (14.5)+6) \div(\text { (37.38- } \\
0.5 * 6 * \sec (14.5)) \\
\mathrm{TR}=9.88 \mathrm{~N}-\mathrm{m}
\end{gathered}
$$

Similarly torque required to lower the lower the load can be given as;

$$
\begin{gathered}
\mathrm{TR}=3000 * 7.38 / 2 *(0.5 \text { [ } * 7.38 * \sec (14.5)- \\
6) \div(\text { ? } 7.38+0.5 * 6 * \sec (14.5)) \\
\mathrm{TR}=2.50 \mathrm{~N}-\mathrm{m}
\end{gathered}
$$

Condition for self locking

The load would lower itself without any external force if

$$
\mu \pi \mathrm{dm}<\mathrm{L}
$$

and some external force is required to lower the load if

$$
\mu \pi \mathrm{dm} \geq \mathrm{L}
$$

This is therefore the condition for self-locking

Table comparison for power screw material

\begin{tabular}{|l|l|l|}
\hline Material & Tensile strength & Yield strength \\
\hline $\begin{array}{l}\text { Plain carbon } \\
\text { steel }\end{array}$ & $420 \mathrm{~N} / \mathrm{mm} 2$ & $351 \mathrm{~N} / \mathrm{mm} 2$ \\
\hline Alloy steel & $723 \mathrm{~N} / \mathrm{mm} 2$ & $620 \mathrm{~N} / \mathrm{mm} 2$ \\
\hline Aluminium & $689-950 \mathrm{~N} / \mathrm{mm} 2$ & $100-300 \mathrm{~N} / \mathrm{mm} 2$ \\
\hline Bronze alloy & $650 \mathrm{~N} / \mathrm{mm} 2$ & $124 \mathrm{~N} / \mathrm{mm} 2$ \\
\hline Plastics & $15-85 \mathrm{~N} / \mathrm{mm} 2$ & $30-95 \mathrm{~N} / \mathrm{mm} 2$ \\
\hline
\end{tabular}

\section{ANALYSIS AND RESULTS}

\subsection{Finite Element Analysis of Chassis}

The finite element analysis method is the most efficient technique to analyse the designed component effectively. The main loads on the chassis are from the suspension system and reactional forces of the driver and engine (the main masses) to the lateral longitudinal and vertical accelerations. The chassis is analyzed for three types of loading. And Maximum stress, deflection behaviour and FOS is observed in each case.

- Vertical bending load.

- Torsional loading.

- Lateral forces.

The chassis is analysed considering the forces with magnitude that of $2 \mathrm{~g}$ and $3 \mathrm{~g}$

\section{Vertical Bending Load}

Vertical bending analysis is done to check the ability of the structure to withstand the vertical forces acting on it. While performing the stated analysis, one end of the chassis is kept fixed (by applying constrains) while vertical load is applied in the centre portion of the chassis. This analysis is a check for the displacement in the chassis members.
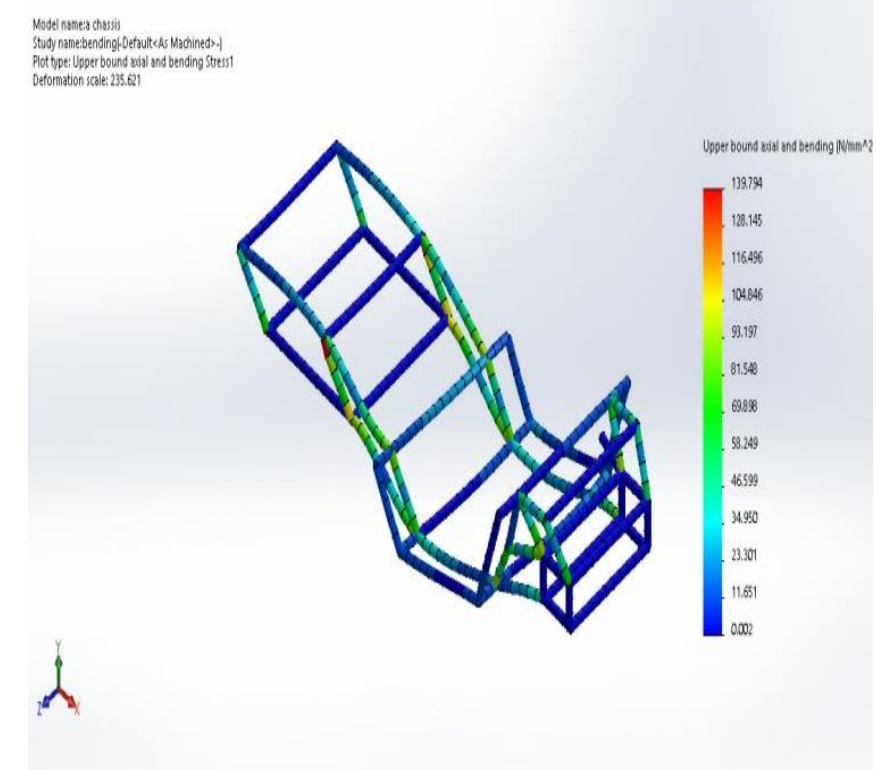

Stress:

Stress analysis for vertical loading.

Min - $0 \mathrm{~N} / \mathrm{mm}^{2}$

Max.- $139.794 \mathrm{~N} / \mathrm{mm}^{2}$ 


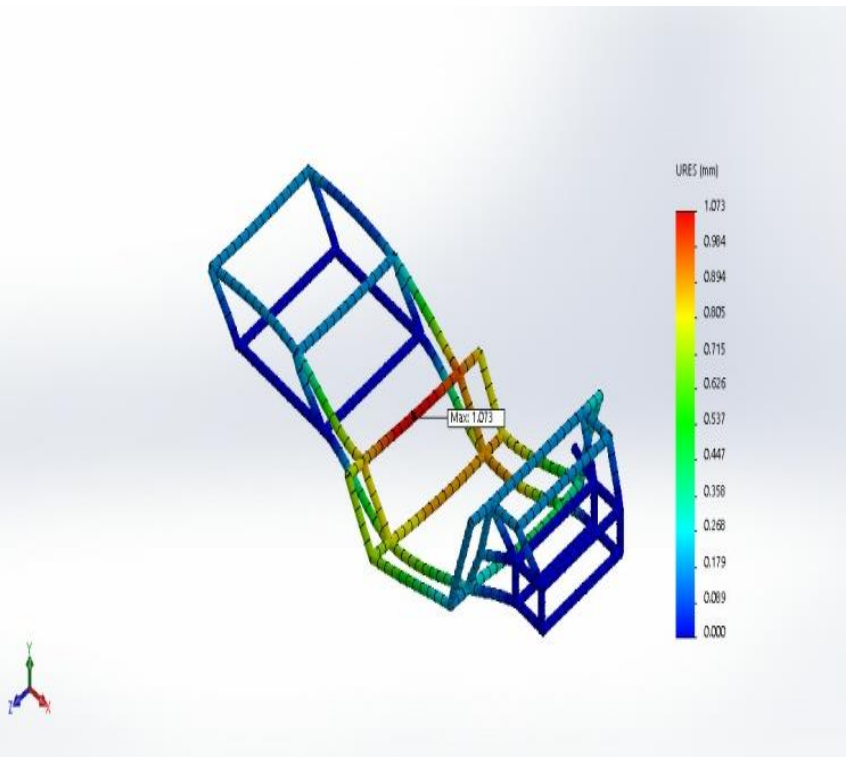

Displacements for torsional loading

Displacement:

Min - $0 \mathrm{~mm}$

Max - $1.07321 \mathrm{~mm}$

\section{Torsional Loading}

The torsion analysis is performed to check the effect of twisting moment on the structure. Herein the front portion of the chassis was kept fix (apply constrain) while the twisting force was applied to rear section of the chassis.

The force equivalent to $1.5 \mathrm{~g}$ was applied to the chassis

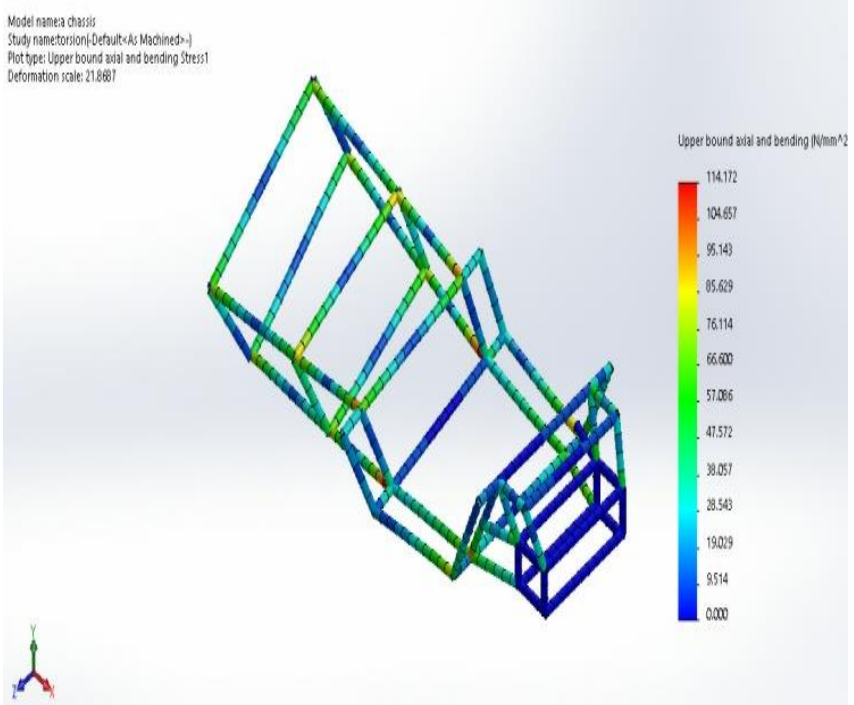

Stress analysis for torsional loading.

Stress:

Min $-0.00 \mathrm{~N} / \mathrm{mm}^{2}$

Max.- 114.172 N/mm²

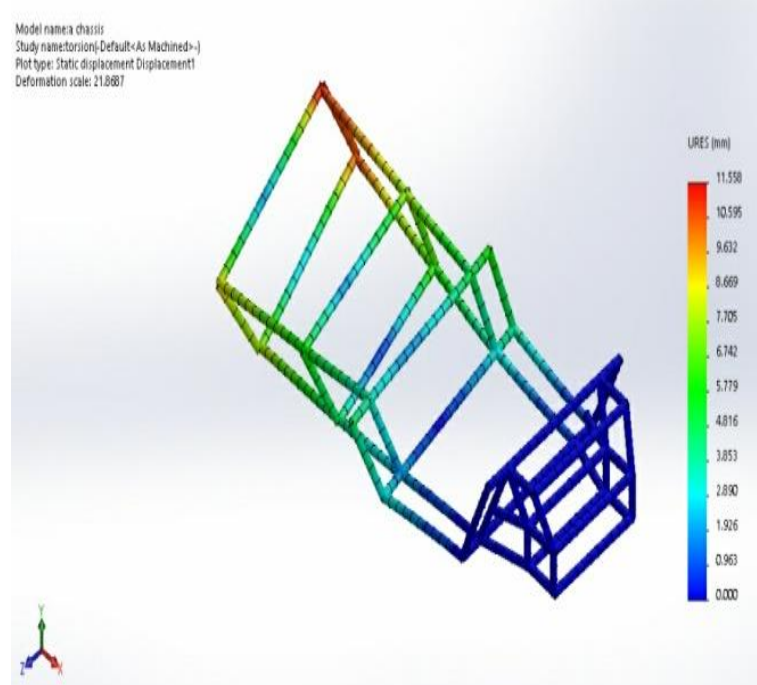

Displacements for torsional loading

Displacement:

Min - $0 \mathrm{~mm}$

Max - $11.5581 \mathrm{~mm}$

\section{Lateral Forces}

This analysis is done by applying the forces in the lateral plane of the chassis. It is usually done to study the effect of side impact forces on the structure. The equivalent to $1 \mathrm{~g}$ was applied while performing the analysis

\section{Modet namer absis}

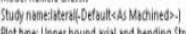

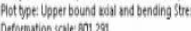

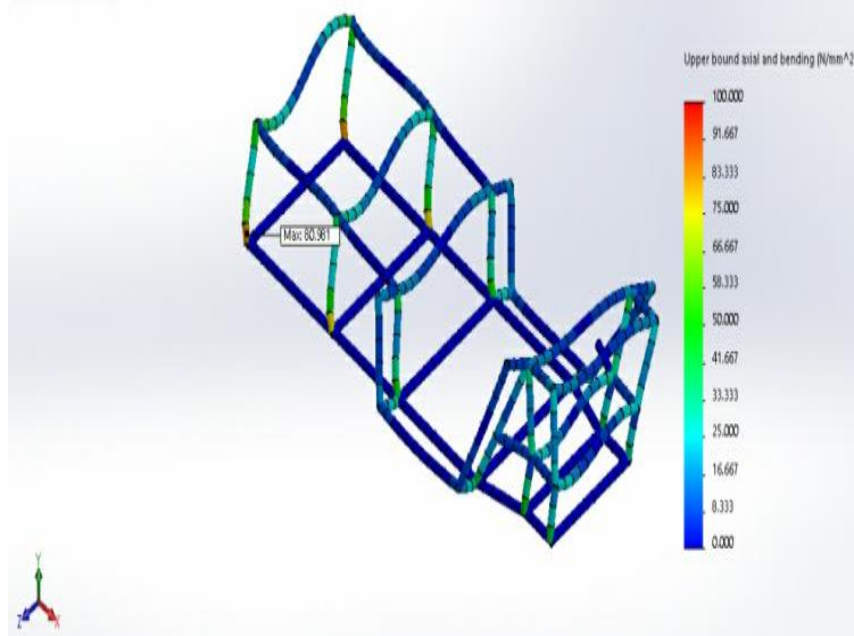

Stress analysis for lateral loading

Stress:

Min - $0 \mathrm{~N} / \mathrm{mm}^{2}$

Max.- $80.9812 \mathrm{~N} / \mathrm{mm}^{2}$ 

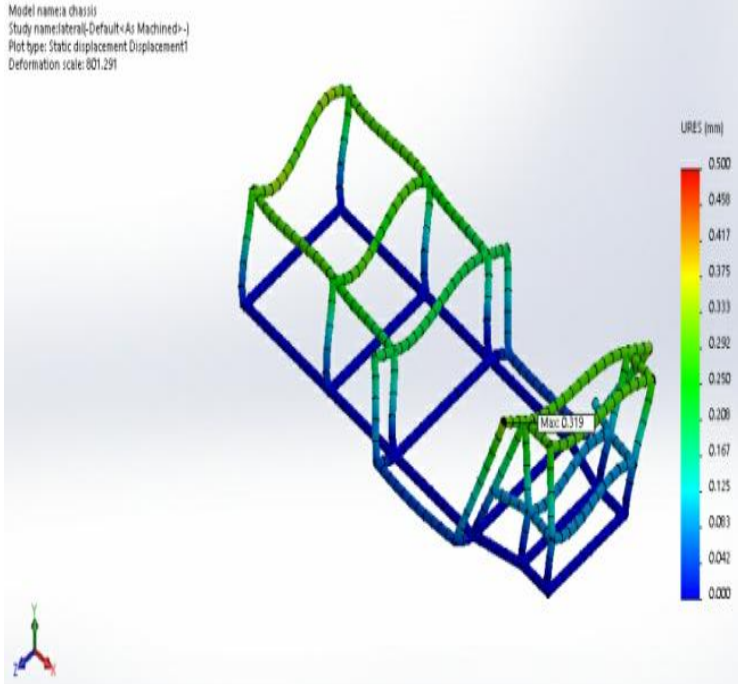

Displacements for lateral loading

Displacement:

Min - $0 \mathrm{~mm}$

Max - $0.318601 \mathrm{~mm}$

\subsection{Finite Element Analysis of Power Screw}

\subsubsection{Bending Loading}

For checking the effect of bending and compressive forces acting on the screw. The force equivalent to $10 \mathrm{kN}$ was applied on the midpoint of screw by fixing both ends

As seen from the results below the chassis can efficiently withstand the forces, while a majority of the elements lay within the permissible force withstanding limits.

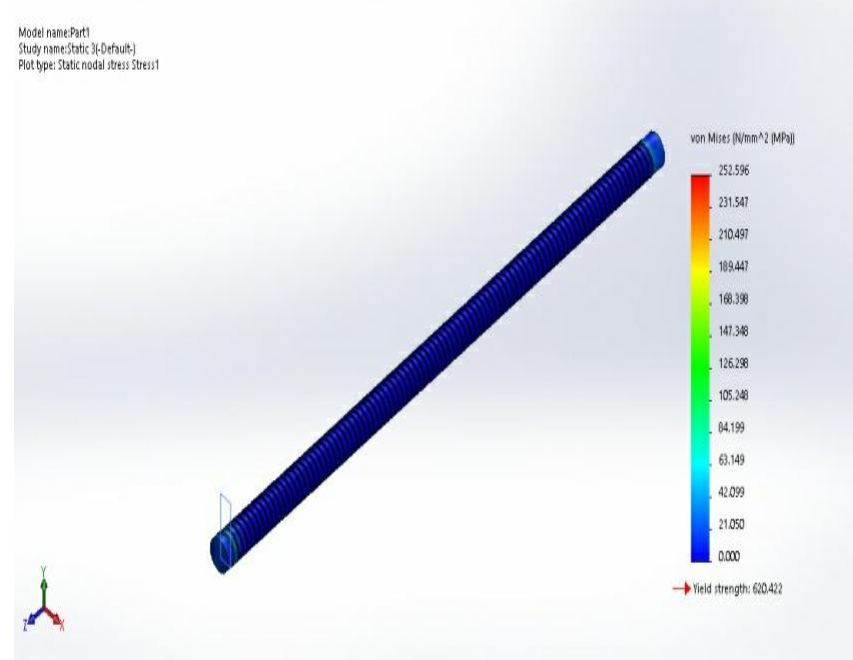

Stress Analysis for bending

Stress:

Min - $0 \mathrm{~N} / \mathrm{mm}^{2}$

Max.- $252.596 \mathrm{~N} / \mathrm{mm}^{2}$

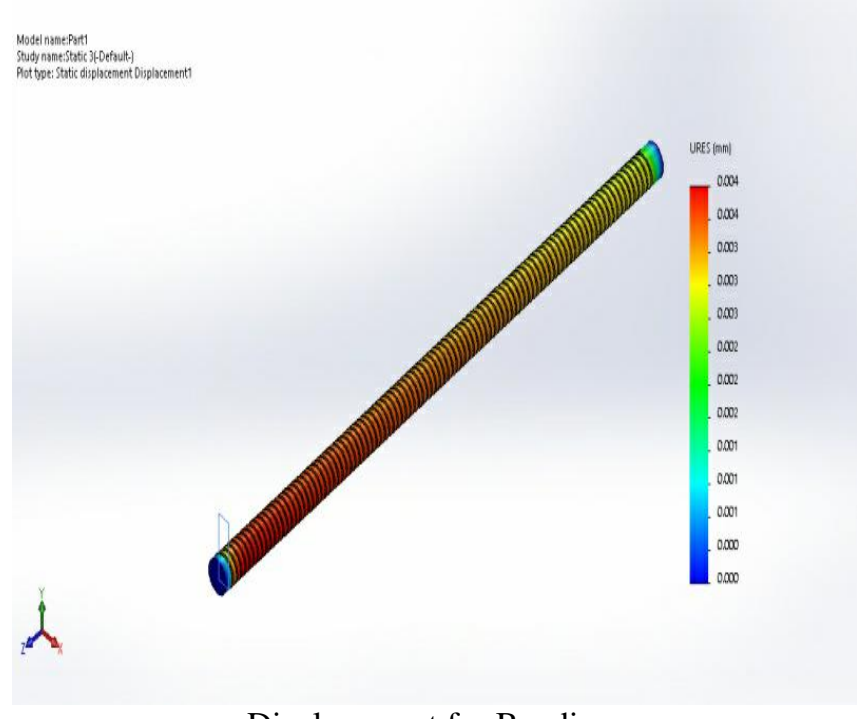

Displacement for Bending

Displacement:

Min - $0 \mathrm{~mm}$

Max $-0.00399916 \mathrm{~mm}$

\subsubsection{Axial Loading}

For checking the effect of axial forces acting on the power screw due to vertical loads acting over it. While performing the analysis, the constrains were applied to both the ends of the power screw and the forces were applied on the threads of the screw.

$30 \mathrm{KN}$ of Axial compressive force are applied on the Screw Threads.
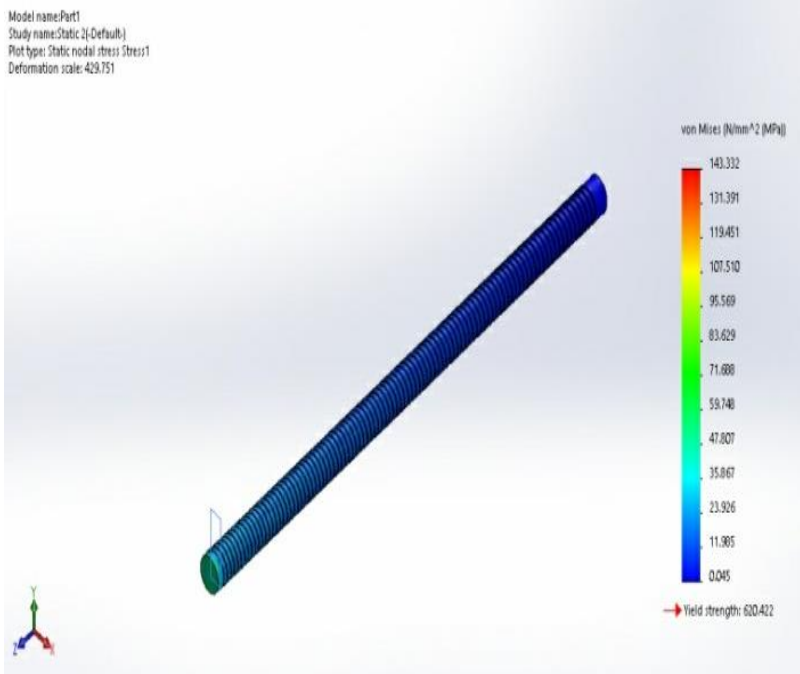

Stress analysis for Axial Loading

Stress:

Min - $0 \mathrm{~N} / \mathrm{mm}^{2}$

Max.- 143.332 N/mm² 


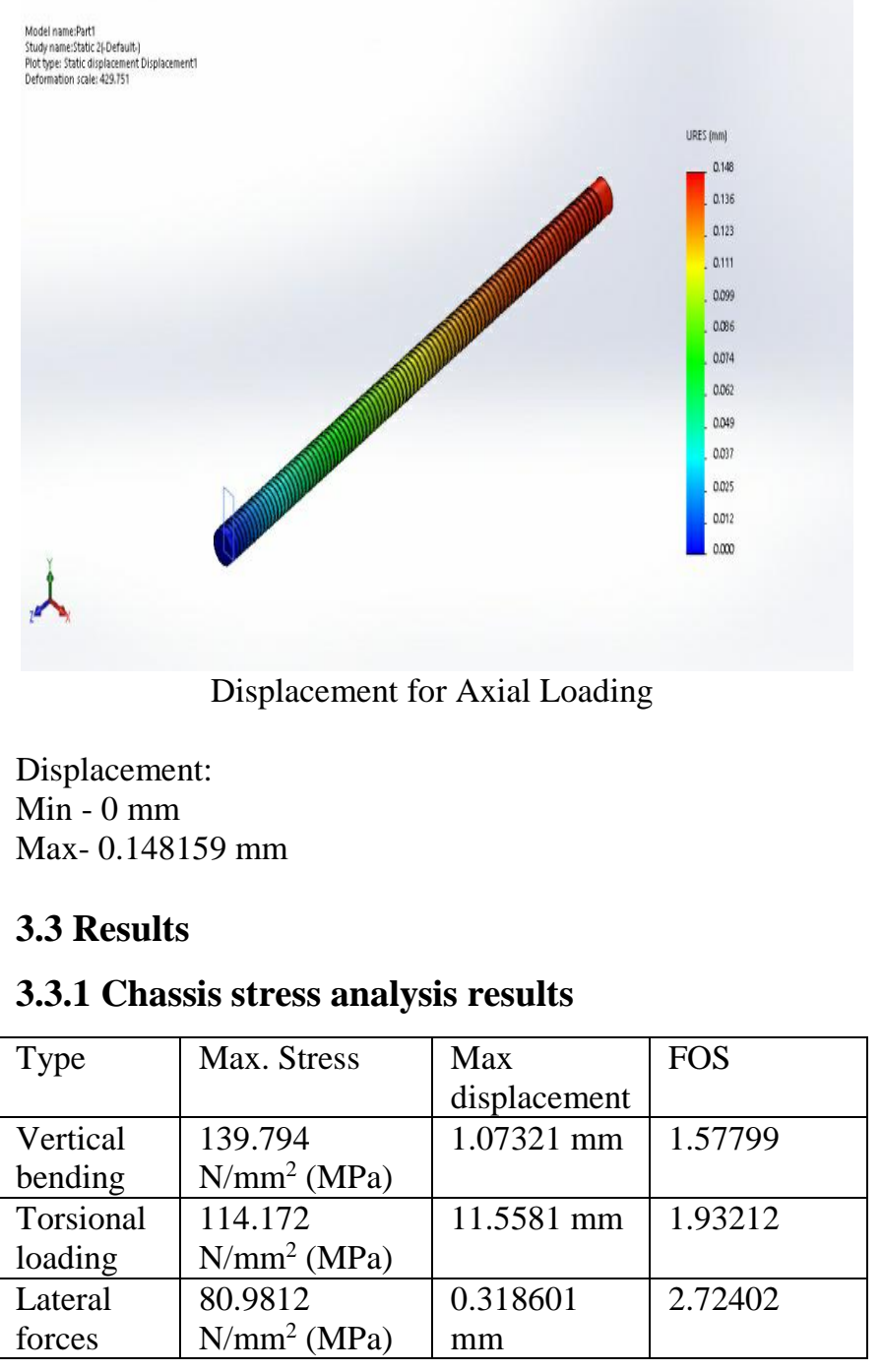

\subsubsection{Power Screw analysis result}

\begin{tabular}{|c|c|c|c|}
\hline Type & Max. stress & $\begin{array}{l}\text { Max } \\
\text { displacement }\end{array}$ & FOS \\
\hline $\begin{array}{l}\text { Bending } \\
\text { Loading }\end{array}$ & $\begin{array}{l}252.596 \\
\mathrm{~N} / \mathrm{mm}^{2}\end{array}$ & $\begin{array}{l}0.00399916 \\
\mathrm{~mm}\end{array}$ & 2.5 \\
\hline $\begin{array}{l}\text { Axial } \\
\text { loading }\end{array}$ & $\begin{array}{l}143.332 \\
\mathrm{~N} / \mathrm{mm}^{2}\end{array}$ & $\begin{array}{l}\text { Max- } \\
0.148159 \\
\text { mm }\end{array}$ & 4.3 \\
\hline
\end{tabular}

\section{CONCLUSION}

The conclusions drawn from this project work can be stated as follows

The platform for variable wheelbase vehicle was successfully design

- Standard will be defined, so that anywhere in the world, can be used by certified vehicles no matter who have produced the vehicle.

- $\quad$ To validate the design, the platform was analyzed using SOLIDWORKS software for Vertical bending load, Torsion loading, lateral forces. The design is safe.

- The power screw with acme threads to expand the wheelbase by $500 \mathrm{~mm}$ is effectively designed and analyzed for Axial and Bending forces. The mechanism can be expanded successfully within limits.

- Technology which is able to handle the huge challenges facing the transport sector in the future.

\section{REFERENCES}

[1]. Manpreet Singh Bajwa (2013) "Static load analysis of TATA super ace chassis and itsverification using solid mechanics.'International Journal of Mechanical and Production Engineering, ISSN: 2320-2092,

[2]. Mohamad Sazuan Bin Sarifudin (2012)“Design and analysis of car chassis” ,Faculty of Mechanical Engineering University of Malaysia Pahang.

[3]. Hossein sheikhha, Frank Seifert (2010) "motor vehicle with extendible vehicle body", United states patent US $8,226,144$ B2.

[4]. Sandip Godse, Prof. D.A.Patel (2013) "Static Load Analysis Of Tata Ace Ex Chassis And Stress Optimisation Using ReinforcementTechnique" ,S.P.C.E, Visnagar, Gujarat, INDIA.

[5]. Suraj B Patil , Dinesh G Joshi (2015)“ STRUCTURAL ANALYSIS OF CHASSIS: A REVIEW”, RMD Sinhgad School of Engineering, Maharashtra, India.

[6]. Monika S. Agrawal(2015)"Finite Element Analysis of Truck Chassis Frame", Trinity Collegeof Engineering Pune, India.

[7]. William Lark, Jr. (2005) "Optimizing vehicle and urban efficiencies through a shared adaptive platform", massachusetts institute of technology

[8]. Thin-Lin Horng (2013)"The Study of Contact Pressure Analyses and Prediction of Dynamic Fatigue Life for Linear Guideways System”, Kun-Shan University, Tainan, Chinese Taipei.

[9]. William Andrews (2000) "Variable wheel base vehicle", CambeWarra, Australia Patent Number 6065556

[10]. HIWIN, Pvt.Ltd.(2007) "Technical Information of Linear Guideway”, HIWIN, Ltd., Taichung.

[11]. Francois de Gaillard (2003)"Motor vehicle with a convertible passenger compartment", Mouilleronenpareds (FR), Patent No. US 6,517,135 B2.

[12]. Jannis D.G. van Kerkhoven (2008) "Design of a Formula Student race car chassis".

[13]. Alejandro Diaz (2014) "FSAE 2015 Chassis and Suspension".

[14]. Chun-Min Lu, Taipei Hsien(2006)“Hidden type sliding rail assembly auto locking structure for drawer",United States,Pub. No.: US 2007/0278919 A1.

[15]. Roy H. Tull, Long Beach, Calif. (1937) "Telescoping extension for trucks and thralers",Long Beach, Calif, Patent No.,2,119,800.

[16]. Clarence W. Kronbetter, St. Joseph. (1991)“Latching mechanism for slidingmembers",Patent Number: 5,028,082.

[17]. Kenneth B. Jacobs (1996)"Method of manufacturing a ladder frame assembly for a motor vehicle",Markham Canada,Patent Number: 5,561,902.

[18]. Michael J. Flowers,Edward J. Hanker (2001) "Variable wheelbase personal 3,945,449 a 3/1976 Ostrowmobility vehicle”,United States,Patent No.: US 6,530,445 B1. 
[19]. KatsunoriAsogawa (2007), "Variable wheel positioning vehicle",United States,Publication number US7823673 B2.

[20]. Power Screw drives and their efficiency, Version $2 \mathrm{ME}$, IIT Kharagpur, pp 6.1.1- 6.1.4

[21]. Bhandari, V B (2007), Design of Machine Elements, Tata McGraw-Hill. 